\title{
Children's understanding of time: A study in a primary history classroom ${ }^{1}$
}

\author{
Glória Solé* - University of Minho, Portugal
}

\begin{abstract}
This paper reports findings from a study of Portuguese primary children's understanding of time and historical time. The research involved two classes (first grade, with 24 students aged 6 to 7, and third grade, with 25 students aged 8 to 9) of primary school students during two school academic years in an urban primary school in northern Portugal. The main aim of the study was to analyse how students from the first to fourth grade of education develop chronological (time) concepts and historical understanding. Different data collection techniques and methodologies were used that allowed for three types of triangulation. Data were collected through semi-structured interviews, open interviews, participant researcher observation, audio data, field notes and class diaries. The research was undertaken by the researcher and the class teacher. The research was carried out though a longitudinal study over two years. At three times during the study, the students were asked to arrange historical pictures in chronological order and to explain their sequences. The research data were analysed using a deductive approach. This allowed the construction of a conceptualization system with parameters, categories and subcategories. The findings suggest that temporal understanding and historical thinking are developed gradually but, significantly, they can be facilitated and accelerated by means of specific social studies/history teaching strategies and pedagogy - that is, an intervention strategy.
\end{abstract}

Keywords: chronology; historical thinking; intervention strategies; triangulation; 6- and 8-year-old students

\section{Introduction}

Historical researchers argue that understanding time is essential to the study of history. Understanding historical time is an important aspect to historical learning, helping students to place historical events, people and changes in a chronological framework and more generally to orient themselves in time (Rüsen, 2007). The understanding of historical time is an indispensable part of history education. It enables students to form their personal identities and enlarges their understanding of the world at large, and it promotes citizenship through equipping students with critical competencies that underpin democratic societies.

For over forty years, children's conceptual understanding of time has been the subject of research. Primary school children's development of temporal (time) conceptual understanding has always been a controversial area of research. Research identifies the central conceptual role of understanding historical time in students' historical thinking and understanding (Downey and Levstik, 1991; Wineburg, 1996; Barton, 2008). There are different research paradigms about what children's conceptual 
understanding of temporality means and its effect on their historical understanding (Thornton and Vukelich, 1988; Stow and Haydn, 2004; Barton, 2008).

Research studies indicate that understanding children's development of the concept of time is, however, fraught with difficulties. Time is a highly complex concept, comprising a variety of areas of understanding, including the mathematical, linguistic and logical, but it is an indispensable component of historical understanding (Stow and Haydn, 2004). Throughout the 1980s, some researchers (Thornton and Vukelich, 1988) reported that 'clock' and 'calendar' time were prerequisites for students' developing a sense of historical time. Other researchers focused on mathematical competence as the important factor in the development of temporal understanding (Friedman, 1982; Hodkinson, 2003).

In contrast to disagreements regarding the place of mathematics in chronological thinking, researchers have generally agreed that language has a central role in the acquisition, development and understanding of time (Fraisse, 1982; Harner, 1982; Wood, 1995; Hoodless, 2002). Indeed, as Stow and Haydn (2004: 88) note, the temporal linguistic dimension 'as the overt symbol of the child's understanding of time, has probably received the most attention in research'. In response to such studies, history educationalists have argued for direct instruction in the language of time as a mode of understanding and communication (Cooper, 1995; Patriarca and Alleman, 1987). Patriarca and Alleman (1987), for instance, suggest direct instruction in temporal concepts, with social studies as the appropriate forum. They conclude that, 'students will need to use and apply temporal concepts and skills in a wide array of subject areas. Furthermore, as the child progresses in school, the demands for temporal understanding increase both quantitatively and qualitatively (ibid.: 274). Recently, researchers have worked with children using visual resources to find out how they understand both history and historical time, especially related to chronology (Barton and Levstik, 1996; Barton, 2002; Harnett, 1993; Hodkinson, 2003; Levstik and Barton, 1996; Foster et al., 1999; De Groot-Reuvekamp et al., 2014; Hofmann-Reiter, 2015; West, 1981; Wilschut, 2012). Several common and consistent findings have emerged from this body of research that use visual sources and student interviews.

West (1981) helped to develop students' skills to interpret different types of visual images, as well as developing concepts of authenticity and time that resulted from the tasks undertaken by them. The student tasks helped to foster a sense of time, revealing that students have greater ability than thought to identify the period of the image and to understand if it is contemporary or not. Harnett (1993) concluded from her study that in the sequencing and dating of images, children aged 5 experienced difficulty when suggesting any reason for the ordering of their images, while older children had less difficulty in explaining why they placed them in a particular order. Harnett also concluded that children have problems when recognizing the duration of time and describing the passage of long periods of time. Barton and Levstik (1996) verified that in their explanations about their ordering of pictures, children know more than they can explain, despite the insistence of the researchers that children try to explain in more detail when asked about the ordering of their pictures. They found that, in general, students' qualitative description of time is associated with elements of their knowledge, rather than the periodization established by historians or used in textbooks.

In all ages, there was a correct student approach to sorting or ordering the pictures, even when the children were often unable to provide explanations as to why the ordering was done correctly. Also, the research carried out by Wilschut (2012) provides evidence that dates and centuries seem to be much less important for students than is often assumed in history education, compared to them being able 
to picture the passage of time. Hodkinson (2003) concluded that the 'performance' was better in students who have been subject to a special programme of teaching of history - an intervention strategy - that deliberately targeted teaching methods that play an essential role in student assimilation of concepts of historical time. Such pedagogy is more important in learning about time than student intelligence, social background or mathematical ability.

Through this current research project, the author found that the concepts of historical time, especially chronology, duration and assimilation of conventional systems of dating, are developed by applying a bespoke curriculum that systematically and consistently uses active teaching methods. Analysing curricula, De Groot-Reuvekamp et al.'s (2014) research study focused on the comparison of the English and Dutch primary curriculum regarding the understanding of historical time. In England, the history national curriculum starts earlier, but the non-chronological structure of the curriculum does not support developing students' understanding of historical time. In the Netherlands, the curriculum starts later, but the contents are mostly taught chronologically. De Groot-Reuvekamp et al. (ibid.: 24) also suggest the 'development of pupils' understanding of historical time requires a thoughtful teaching of the objectives, with regular assessments, good timelines and good planning through all years of primary school', echoing similar findings of West (1981) and Hodkinson (2003).

In my PhD (Solé, 2009) I researched how Portuguese primary students understand both vernacular time and historical time, especially chronological. In the current research project, I sought to analyse and understand primary children's chronological reasoning when they were ordering a set of pictures. I focused more on the kinds of historical and temporal explanations that the students gave at different levels to examine how those distinctions change with age, and particularly to analyse those changes at different moments in their schooling. The research centred on the implementation of a special curriculum with various active pedagogic strategies for learning social studies/history, rather than concentrating on students' passive acquisition of historical knowledge of facts, people or dates. My research project hypothesized that chronology presented through visual images could be a fruitful approach for developing temporal understanding, an approach suggested by similar research described above. In the next section of this paper, I present a case study on one aspect of my research.

\section{Method}

The case study is predominantly a longitudinal descriptive case study (Yin, 2003) that is both qualitative and interpretative (Erickson, 1986). I used qualitative and quantitative data collection, analysis and inference techniques to deepen understanding and corroborate findings (Johnson et al., 2007). According to the research typology proposed by Stake (2000), it could also be considered as an instrumental case study, as I aim to show through the case study how children develop concepts of time and the difficulties felt in the teaching-learning process. The case study also illuminates how this learning is achieved through various teaching strategies and approaches.

\section{Participants}

This case study was carried out with two classes (first grade, with 24 students aged 6 to 7 , and third grade, with 25 students aged 8 to 9) of primary school students during two school years in an urban elementary school in northern Portugal. The student names used are pseudonyms. The school was deliberately chosen by the researcher 
because of ease of accessibility. The participant classes of students were selected as a heterogeneous group in terms of achievement and socio-economic setting, although they should be considered culturally and ethnically as relatively homogeneous.

\section{Research aims and design}

The main research questions were:

- What conceptions and feelings do primary school students have about what history, past, time and change are?

- How did the students' temporal and historical understanding develop after two years of implementing cognitively challenging strategies using different learning processes related to teaching history?

The aims of the study were: (1) to analyse how students from the first to the fourth grade develop time concepts (vernacular time and historical time) and historical understanding with the help of activities that include various strategies to assess the knowledge, understanding and application of the conventional time system; (2) to assess the evolution of historical understanding in relation to the capacity to make inferences and interpretations from sources, to justify sequences of historical events or not; and (3) to establish causal relationships and to explain changes and continuities over time.

\section{Procedures, instruments and collected data}

Different data collection techniques and methodologies were used that allowed for three types of triangulation (Cohen et al., 2000; Denzin, 1970; Kelle, 2006): (1) methodological triangulation (data collection techniques: semi-structured interviews, active participant observation researcher; audio class records; field notes; class diaries and also open interviews to clarify some students' ideas); (2) the triangulation of researchers (the researcher-teacher and the class teachers' research); and (3) time triangulation (it is a longitudinal study carried out over two academic years).

The case study involved two major elements: interviews with the students at the beginning and end of the school year, and a classroom intervention using a set of research-based strategies for teaching and learning social studies/history. At three different times during the research programme, the students were asked to arrange historical pictures in chronological order and explain their arrangements (see Appendix). In this paper, I present findings from the semi-structured student interviews held at the beginning and end of two school years. The interviews were structured to identify changes in the explanations given and in the understanding of historical time before and after a year of instructional intervention, with the aim of examining what students understood about change over time.

The interviews follow the model of Levstik and Barton (1996) and Barton and Levstik (1996). Each interview revolved around asking students to time-order a series of pictures and explain their choices. The researcher asked questions such as: Which is the oldest and which is the most recent? Why did you put this one before that one? What led you to think that this one is older than this one? For the students of the first and second years, I used six historical pictures of family life from different contexts and historical eras. For the students of the third and fourth years, I added another picture to the six (Picture C), making a total of seven pictures for them to sequence. I considered that seven pictures was too many for the younger children to order, and I decided not to use Picture C (1816) in this series because that is closest in time to 
Picture D (1886). Pictures were chosen to represent time sequences that most adults could put into the correct order. They represent family scenes from prehistory to the present day (see Appendix).

The selection of pictures was based on various criteria beginning with a common theme - the family across time. My aim was to cover a large timescale, so that the students would be able to sequence the images regardless of their knowledge. As in the Levstik and Barton (1996) study, I selected social, family and everyday history, which fits much better in the primary school curriculum than political history. I sought to examine the hypothesis that children of this age have more extensive historical knowledge, understanding and skills related to time than argued in previous studies, largely based upon Piagetian theories.

\section{Data analysis and discussion of results}

The data were analysed using a deductive approach, which allowed the construction of a conceptualization system in parameters, categories and subcategories. After transcribing interviews and developing a set of coding categories, I identified coding categories based on the research questions, the system of categories used in the study carried out by Levstik and Barton (1996) and Barton and Levstik (1996), and the children's responses in the interviews. I adopted a strategy of holistic analysis in each interview and developed inferences based on the trends identified in each student's responses. For the process of coding, I constructed several types of tables to compare the answers of the students and more easily identify common patterns.

From this, I established a set of parameters for students' temporal and historical understanding related to the process of ordering a series of pictures (and justifying that order). I identified three types of parameters, each of which integrate a set of categories and subcategories:

1. chronological ordering of pictures

2. process and strategies used in the ordering of pictures

3. ideas about historical change.

Only the data referring to the first two parameters are analysed in this paper.

\section{Chronological ordering of pictures}

We began to analyse a chronological ordering of pictures, identifying different typologies of temporal ordering, trying to identify continuity or change in the typologies made by each student during two school years. The analysis of the ordering of the pictures contributed to greater clarity in inferring which pictures were put in a different ordering and the explanation for that ordering.

At the beginning of the first grade, students exhibited the most diversity in their typologies related to chronological ordering (ten typologies). By the end of the same year, this shrank to four typologies, and at the end of the second grade, students exhibited only three typologies, and these were the most accurate ones. The results suggest a rapid shift in student behaviour, but what is perhaps even more interesting is the rapidity with which the most accurate ordering predominated. By the third and fourth grades, students presented a smaller number of typologies in the chronological ordering of pictures compared to first- and second-grade students, in spite of having one more picture (seven pictures in total) to consider. At the beginning, in the first chronological ordering of pictures, in the third grade there was evidence of seven 
typologies; by the end of the fourth grade only four typologies could be identified. The most frequent changes in the ordering were between the third and the fourth picture (pictures $C$ and D), in the middle of the chronological sequence.

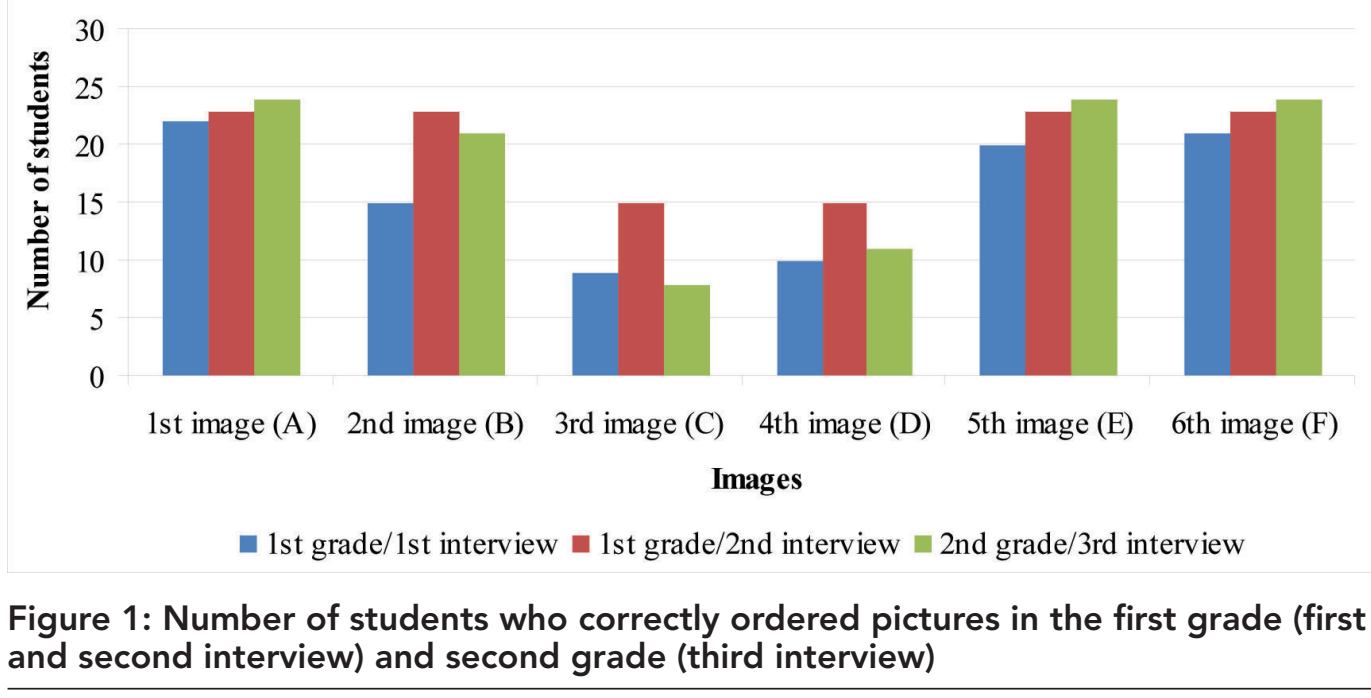

In relation to the total number of pictures ordered correctly, 7 of the 24 students (29 per cent) of first grade in the first interview ordered six pictures correctly. An improvement in their performance at the end of the school year was verified in the second interview: 15 students (62 per cent) put the pictures in the correct order. However, at the end of the second grade (third interview), the students performed less effectively, because only 8 students (33 per cent) could do the task correctly, but 16 students (67 per cent) ordered four pictures correctly and made mistakes only in the middle of the sequence (see Figure 1).

The majority of children in the second grade who changed the order between Picture $\mathrm{C}$ and Picture D based their justification on the cultural and material differences between them, especially their social, economic and technological differences.

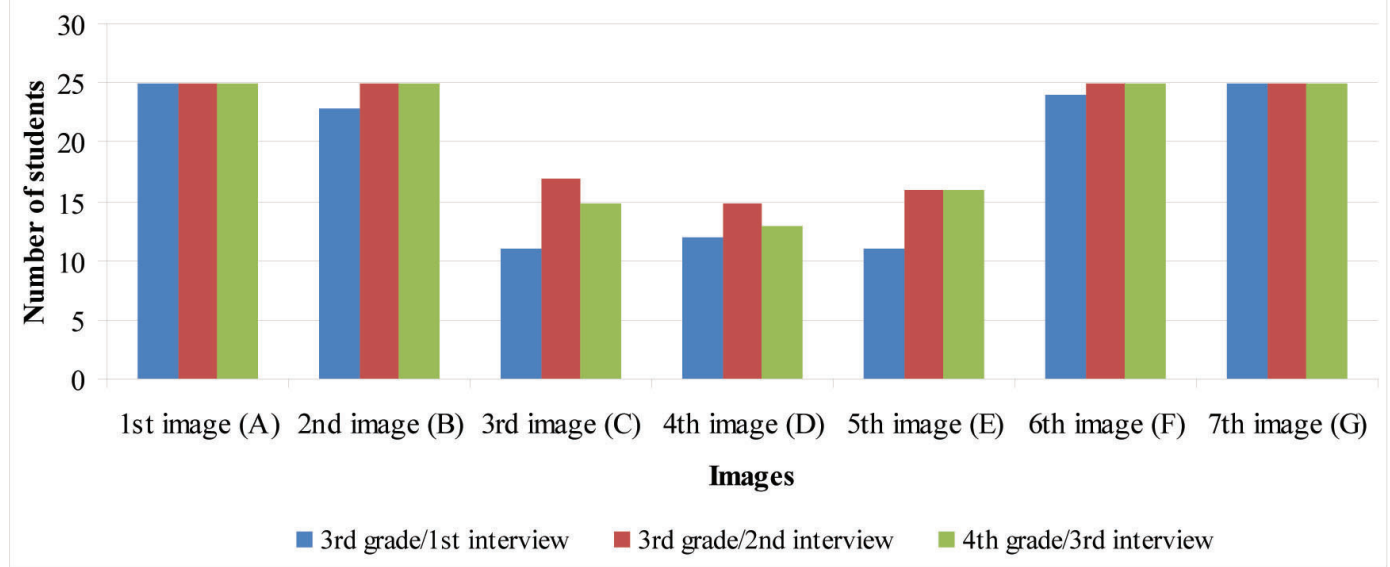

Figure 2: Number of students who correctly ordered pictures in the third grade (first and second interview) and fourth grade (third interview) 
The students of the third and fourth grade did not have difficulty ordering correctly the first two pictures ( $A$ and $B$ ) and the last two pictures ( $F$ and $G$ ) (see Figure 2). Also, the third- and fourth-grade students had more difficulty ordering correctly the pictures in the middle of the sequence (C, D and E). However, at the end of the third grade (second interview), more than half ordered them correctly. At the third grade, 10 of 25 students ( 40 per cent) at the first interview and 15 students ( 60 per cent) at the second interview ordered the pictures correctly, but we verified an unexpected minor inconsistency of the same students at the fourth grade, because only 13 students (52 per cent) did the task correctly. However, this is more than half of the students of the class. These results were not expected considering the results of the exploratory study. In relation to the number of pictures ordered correctly at the beginning of the third grade, this suggested a lower dispersion compared to the first grade, so here the improvement was not so effective. Yet, in the final study, it was greater among the number of students who ordered all pictures correctly. All students, either fourth grade or second grade, placed at least four pictures correctly, but between the third grade and the fourth grade there were significant improvements in ordering five pictures correctly. This contributed to demonstrating less temporal incongruence with both maturational and educational development.

Overall, then, our analysis of students' chronological ordering of pictures suggests increasing student competence, not so much because of the increased proportion of correctly ordered sequences but because of the decrease in ordering typologies from ten at the start of the first grade to three by the end of the second grade. I verified the same outcome in relation to the third and fourth grades, where I identified seven typologies at the beginning of the third grade, reduced to four typologies by the end of the fourth grade.

Quantitative precision can give a misleading impression of children's chronological thinking. To address this, I analysed each interview and generated inferences based on the response trends to understand the process, strategies and explanations given to justify their sequencing of the pictures.

\section{Processes and strategies used in establishing chronological order}

As students participated in the ordering of pictures, I asked them to 'think out loud' about their choices and, afterwards, I asked them a series of questions designed to probe their thinking as they decided which pictures were older than others. The answers and explanations of their choices were recorded and transcribed. I proceeded with a content analysis (Bardin, 1994) of the answers, and I categorized and identified six categories in this parameter - processes and strategies used in ordering a series of pictures, some of them inspired by the work of Levstik and Barton (1996), but focusing on the questions asked to the children, and their answers and explanations. The six categories identified within this parameter, processes and strategies used to order a series of pictures, were:

1. time language and time vocabulary

2. temporal distinctions

3. identifications of change in a material culture

4. process(es) used to explain

5. source of knowledge

6. material support of historical evidence. 


\section{Time language and time vocabulary}

At all grades, students offered a qualitative description of time (they use temporal subjective vocabularies of time such as 'ancient', 'old', 'very old', 'modern', 'recent', 'new'). However, it was the youngest (first and second grade) who used them more frequently to express time, and when they pretended to employ temporal terminology, they used expressions such as: 'long, long time ago', 'long time ago', 'isn't that old', 'is the oldest', 'is a little old', 'is new', 'close to now', 'ancient', 'more ancient', 'new', 'old' and 'from now'. They frequently used the words 'old' and 'new' relative to the temporal dimension in their argumentation - the word 'old' meaning 'ancient', and the word 'new' meaning 'recent'. The students at the end of third grade attempted to use more objective, sophisticated time language, and spoke of time comparatively: 'It is [more] ancient than that'; 'it is newer than that'. For example, Ricardo Manuel (end of third grade) justified his ordering of pictures by using qualitative time language but distinguished comparatively when going beyond the temporal world. In that way, he considered Picture $C$ to be older than picture $D$, and explained why:

Because that one it seems more ancient than that one, because the clothes were used in oldest time, and they are old. And the portrait seems [to have] ancient peoples. However, in that one [Picture D] the clothes are better and new. They already have tables, new lamps. They have a manservant. The portraits are more recent.

The ability to use the conventions of a dating system is unusual before fourth grade in Portuguese schools; only a few younger students used expressions to describe a historical period. The data suggest that dating has little meaning before the third grade, but although several students, including the youngest, recognized that some pictures were separated by a larger numerical interval than others, only the oldest could estimate the time interval between them. This ability to date chronologically is similar to that found in other studies (Levstik and Barton, 1996; Barton, 2002; Hodkinson, 2003).

\section{Temporal distinction}

At all grades, students reported dichotomies between the pictures. All students recognized which were the oldest and the youngest (meaning most recent) pictures, but the quantity, complexity and sophistication of their expressions increased gradually with their grades.

The majority of students at the first and second grades used the dichotomous expressions 'older/oldest/younger/youngest' when they compared the first picture with the others - 'It is the oldest among that one, that one and that one' (Guilherme, beginning first grade) - or between two or more pictures - 'Because that one is a little older than that one' (Catarina, end first grade).

At the end of third grade and fourth grade, they used the dichotomous generalization 'ancient/recent' when they justified the position of the first picture and the last pictures - 'That one without any doubt is the oldest and that is the youngest' (Isidro, end third grade) - and the dichotomous 'distant/nowadays' - for example, this generalization was used by Júlio Manuel when justifying the position of Picture $E$ in relation to the other pictures, inferring markers of material culture such as clothes and buildings: 'That one is close to the present day because they have a modern house and clothes'.

Also, in all grades, the students' attempted to compare the pictures with the present day, but the youngest (first and second grades) did this in a descriptive way. 
They compared the pictures based on markers of material culture, reported what did not exist in the past, and manifested their conception of a deficient past.

\section{Identifications of change in a material culture}

In justifying the placement of the pictures in sequence, students used material culture and daily life (clothes, housing, things for the house, technological resources), as well as social and economic indicators, as time markers, as the examples show. Yet in the fourth grade, some students identified the correct period by what people in the photographs were wearing. The students also compared the buildings, their size, the materials used in their construction, the apparent comfort and the domestic artefacts. When they compared Picture B to the others, especially Pictures $C$ and D (first and second grade), or C, D and E (third and fourth grade), the oldest students gave more details in their observations and enhanced the details with temporal contextualization. Among the students from the second, third and fourth grades, I found changes in the explanations presented at the beginning and end of the year, showing more acute visual perception and greater, more sophisticated understanding and explanation.

\section{The process used to explain}

The research data showed that to support their sequential ordering of pictures, the students employed a range of explanatory processes: narrative process, descriptions of what they saw in pictures, explanation using their experience, or various sources of historical knowledge about the chronological and historical information the pictures reveal.

The research data indicated that the explanations given by the youngest students (first and second grades) for their ordering of the images are relatively deficient in content, even for those who put them in the correct order. For most of them, this justification is based on a mere description of what they see in the image, particularly in the material culture and daily standards of living. Some of these students also present a narrative explanation, creating a story and bringing the characters to life, and some think that they are the same characters in the different images. The pattern of merely describing the pictures decreased in the third and fourth grades.

\section{Source of knowledge}

Other students used another strategy, they employed generic knowledge in the explanations given, knowledge acquired in various contexts: books, media, visits to monuments and sites, and from their families and friends. It was also interesting that in the first grade, students referred to the catechism, using their education in Catholicism to help understand the images. However, the youngest did not apply their knowledge correctly, given the mistakes in their explanations. The students gradually improved their performance and knowledge acquired in various contexts, but only at the end of fourth grade did they apply and reveal more (and) explicit historical knowledge acquired in a school syllabus when they justified their ordering of the pictures.

\section{Material support to historical evidence}

The category, material support, meaning the quality of the images (colour, tonality), was used by few students to justify the ordering of the images, although some students used it together with other strategies. Probably it was not a problem for the students (compare with other studies, such as Harnett, 1993; Foster et al., 1999) because all the 
pictures used had colour, however there are technical quality differences that even the youngest will recognize.

\section{Conclusions}

The data from the research study reveal the students' capacity to sequence events, and that their justifications become gradually more elaborate and sophisticated, establishing causal relationships, recognizing changes and continuities over time. The improvement in the quality of students' participation in the tasks of sequencing pictures related to time also proved the importance of mediated intervention, an intervention strategy (see Barton, 2002). This study researched the effectiveness of a classroom intervention strategy, using a set of research-based approaches and protocols (schemes of work, lesson plans and resources) for teaching and learning social studies/ history. This long-term, systematic approach involves effective planning throughout the primary school years, involving a pedagogy integrating timelines, pictures, artefacts, storytelling, legends, narratives and genealogies. The triangulation of the research data demonstrated a more sophisticated level of thought about historical time during the two academic years when they undertook the time tasks. It also revealed that when the students worked with visual sources, they used various process and tools to explain (in dialogue) their reasoning about historical time for sequencing the pictures.

At the level of chronological understanding, the students used qualitative time vocabulary, gradually replaced by the conventional time systems as they are learnt, and then linking the various subsystems related to time. The findings suggest that most of the students younger than third grade often did not understand the numerical meaning of dates, but recognized differences between times and knew a great deal about historical time, as Barton (2008) argued and other researchers have corroborated. This case study confirmed that dates are problematic for young students, but it also illustrates some aspects of their chronological understanding.

I also found, as in previous research, that the students had developed a qualitative description of time. The data showed that the students' explanation of their ordering of the sequences of pictures employed diverse, increasingly sophisticated explanatory processes. Narrative processes and descriptions of what they see in pictures are most used by the youngest. This merely descriptive pattern decreases in the third and fourth grade. However, those students who used observation produced detailed description of what they saw, and could produce some generalizations, making inferences and deductions.

Challenging tasks using visual sources are a positive way to develop an understanding of historical time. They give students opportunities not only to understand change but also to learn about life during a variety of historical periods. Through these visual tasks, I also verified that the students have more extensive historical knowledge and understanding than previously thought: they have increasingly sophisticated semantic networks with developing substantive, positivistic propositional and syntactic, procedural disciplinary conceptual nodes. The students used the historical information they had learned in different social and educational contexts to make sense of time. In order to develop a sense of chronological time, based on my research I suggest the importance of using a wide and extensive range of visual clues of various historical periods and social contexts, particularly those related to social and material culture (for example, family life, fashion, buildings and technology). For the discourse on history education, this supports the importance of building on students' prior knowledge involving the use of visual images, particularly those with details of social, cultural and everyday life. 
In teaching primary history, it is vital to focus on social and material life, as these are the aspects of history that students find most useful in making sense of time, rather than political history. The Portuguese national curriculum for social studies/history (ME, 1990, 2004) does not have this perspective; it emphasizes a canon of the most important political events, for example those commemorated in national holidays. Nevertheless, recent textbooks are already suggesting changes in the historical content of some periods. Teachers undergoing training at universities are learning new didactics and strategies based upon both constructivism and new conceptions of teaching history to young children grounded in viewing history as enquiry and investigation of sources. This requires a continuous programme of teaching activities involving chronological time (for example, using visual sources to explain or sequence, timelines and narratives), exposure to many different periods, dating and measuring time between them that contribute to children's ability to refine and elaborate ideas about past times. From a pedagogical perspective, this study suggests that certain factors are of crucial importance in establishing how history should be taught. In particular, teachers should give children the opportunity to work with significant historical materials that are explicitly chosen to develop their chronological understanding and temporal awareness.

The empirical evidence from the triangulation of the data of this research project supports the conclusion that teachers' pedagogical approaches and activities, grounded in the disciplinary structure of history as a challenging, evidentially based problem-solving subject with specific 'thinking history' processes and skills, are the main factors in the development of children's temporal understanding, a conclusion confirmed also by the teachers in the final interview of the research programme. This case study also suggests that students' acquisition of chronological concepts and historical understanding develop gradually, but can be accelerated and deepened through specific, focused pedagogical history teaching strategies and their implementation, which social studies and humanities curricula can incorporate.

\section{Notes on the contributor}

Gloria Solé is an assistant professor at the University of Minho, Institute of Education (Portugal). She has a PhD in child studies from the University of Minho with a thesis titled 'Primary History: Time concepts and historical understanding in children and context for their development'. Her research interests are in history education, historical cognition (especially students' understanding of historical time, knowledge and historical thinking), analysis of textbooks and heritage education.

\section{Note}

1 This work is funded by CIEd - Research Centre on Education, projects UID/CED/1661/2013 and UID/CED/1661/2016, Institute of Education, University of Minho, through national funds of FCT/ MCTES-PT.

\section{References}

Bardin, L. (1994) Análise de Conteúdo. Lisbon: Edições 70.

Barton, K.C. (2002) " "Oh, that's a tricky piece!": Children, mediated action, and the tools of historical time'. Elementary School Journal, 103 (2), 161-85.

Barton, K.C. (2008) 'Visualizing time'. In Levstik, L.S. and Barton, K.C. Researching History Education: Theory, method, and context. New York: Routledge, 61-70. 
Barton, K.C. and Levstik, L.S. (1996) "'Back when God was around and everything": Elementary children's understanding of historical time'. American Educational Research Journal, 33 (2), 419-54.

Cohen, L., Manion, L. and Morrison, K. (2000) Research Methods in Education. 5th ed. London: RoutledgeFalmer.

Cooper, H. (1995) History in the Early Years. London: Routledge.

De Groot-Reuvekamp, M.J., Van Boxtel, C., Ros, A. and Harnett, P. (2014) 'The understanding of historical time in the primary history curriculum in England and the Netherlands'. Journal of Curriculum Studies, 46 (4), 487-514.

Denzin, N.K. (1970) The Research Act: A theoretical introduction to sociological methods. Chicago: Aldine.

Downey, M. and Levstik, L. (1991) 'Teaching and learning history'. In Shaver, J.P. (ed.) Handbook of Research on Social Studies Teaching and Learning. New York: Macmillan, 400-10.

Erickson, F. (1986) 'Qualitative methods in research on teaching'. In Wittrock, M.C. (ed.) Handbook of Research on Teaching. 3rd ed. New York: Macmillan, 119-61.

Foster, S.J., Hoge, J.D. and Rosch, R.H. (1999) 'Thinking aloud about history: Children's and adolescents' responses to historical photographs'. Theory and Research in Social Education, 27 (2), 179-214.

Fraisse, P. (1982) 'The adaptation of the child to time'. In Friedman, W.J. (ed.) The Developmental Psychology of Time. London: Academic Press, 113-40.

Friedman, W.J. (1982) 'Conventional time concepts and children's structuring of time'. In Friedman, W.J. (ed.) The Developmental Psychology of Time. London: Academic Press, 171-208.

Harner, L. (1982) 'Talking about the past and the future'. In Friedman, W.J. (ed.) The Developmental Psychology of Time. London: Academic Press, 141-69.

Harnett, P. (1993) 'Identifying progression in children's understanding: The use of visual materials to assess primary school children's learning in history'. Cambridge Journal of Education, 23 (2), 137-54.

Hodkinson, A.J. (2003) 'Primary Children's Developing Conceptions of Historical Time: Analysing approaches to teaching and learning'. Unpublished PhD thesis, University of Lancaster.

Hofmann-Reiter, S. (2015) Zeitverständnis am Übergang von der Grundschule zur Sekundarstufe: Empirische Erkundungen der Geschichtsdidaktik. Innsbruck: StudienVerlag.

Hoodless, P.A. (2002) 'An investigation into children's developing awareness of time and chronology in story'. Journal of Curriculum Studies, 34 (2), 173-200.

Johnson, R.B., Onwuegbuzie, A.J. and Turner, L.A. (2007) 'Toward a definition of mixed methods research'. Journal of Mixed Methods Research, 1 (2), 112-33.

Kelle, U. (2006) 'Combining qualitative and quantitative methods in research practice: Purposes and advantages'. Qualitative Research in Psychology, 3 (4), 293-311.

Levstik, L.S. and Barton, K.C. (1996) "“They still use some of their past": Historical salience in elementary children's chronological thinking'. Journal of Curriculum studies, 28 (5), 531-76.

ME (Ministério da Educação) (1990) Programa do $1^{\circ}$ Ciclo do Ensino Básico, Lisboa: Direcção Geral do Ensino Básico e Secundário.

ME (Ministério da Educação) (2004) Organização Curricular e Programas. Editorial do Ministério da Educação.

Patriarca, L.A. and Alleman, J. (1987) 'Studying time: A cognitive approach'. Social Education, 51 (4), 273-7.

Rüsen, J. (2007) 'Memory, history and the quest for the future'. In Cajani, L. and Ross, A. (eds) History Teaching, Identities, Citizenship. Stoke-on-Trent: Trentham Books, 13-34.

Solé, G. (2009) 'A História no 1. ${ }^{\circ}$ Ciclo do Ensino Básico: A concepção do tempo e a compreensão histórica das crianças e os contextos para o seu desenvolvimento'. Unpublished PhD thesis, Universidade do Minho.

Stake, R.E. (2000) 'Case studies'. In Denzin, N.K. and Lincoln, Y.S. (eds) Handbook of Qualitative Research. 2nd ed. Thousand Oaks, CA: SAGE Publications, 435-54.

Stow, W. and Haydn, T. (2004) 'Issues in the teaching of chronology'. In Arthur, J. and Phillips, R. (eds) Issues in History Teaching. London: RoutledgeFalmer, 83-97.

Thornton, S.J. and Vukelich, R. (1988) 'Effects of children's understanding of time concepts on historical understanding'. Theory and Research in Social Education, 16 (1), 69-82.

West, J. (1981) 'Primary school children's perception of authenticity and time in historical narrative pictures'. Teaching History, 29, 8-10.

Wilschut, A. (2012) Images of Time: The role of a historical consciousness of time in learning history. Charlotte, NC: Information Age Publishing. 
Wineburg, S.S. (1996) 'The psychology of learning and teaching history'. In Berliner, D.C. and Calfee, R.C. (eds) Handbook of Education Psychology. New York: Macmillan, 423- 7.

Wood, S. (1995) 'Developing an understanding of time - sequencing issues'. Teaching History, 79, 11-14.

Yin, R.K. (2003) Case Study Research: Design and methods. 3rd ed. Thousand Oaks, CA: SAGE Publications.

\section{Appendix}

\section{Pictures used in the research}

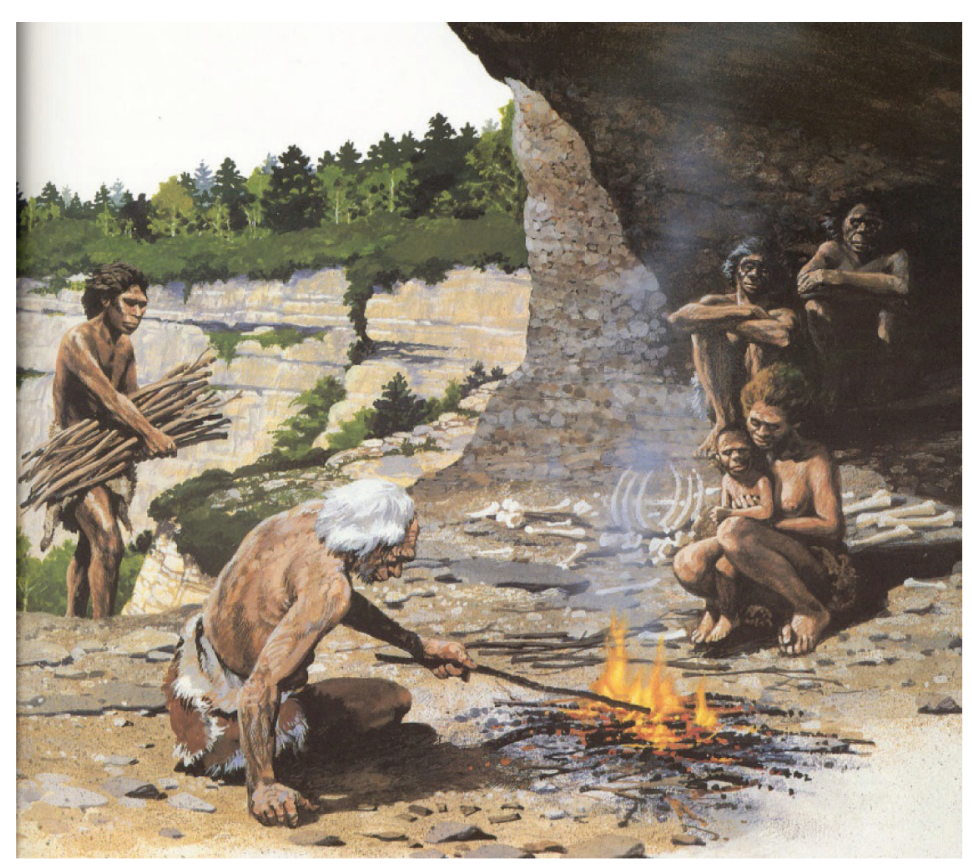

Picture A: Drawing of a prehistoric family, in a cave, around a fire (Enciclopédia da Humanidade, 1990: 69)

Every effort has been made to seek permission from the copyright holder 


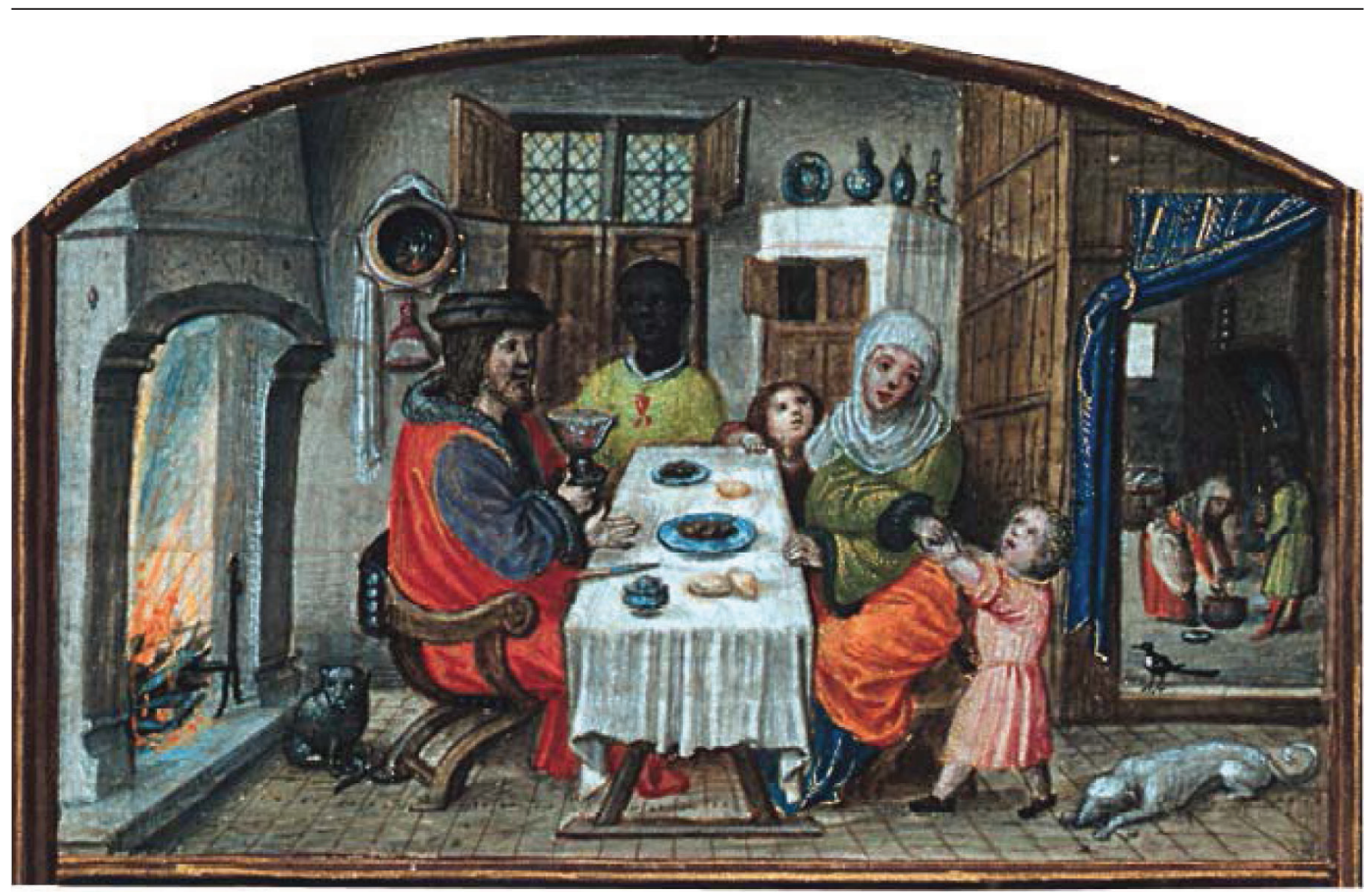

Picture B: Illumination from the sixteenth century with a family at a table, served by a slave (Livro de Horas de D. Manuel, by António de Holanda, c.1517-38)

Reproduced with kind permission of the Museu Nacional de Arte Antiga, Lisbon

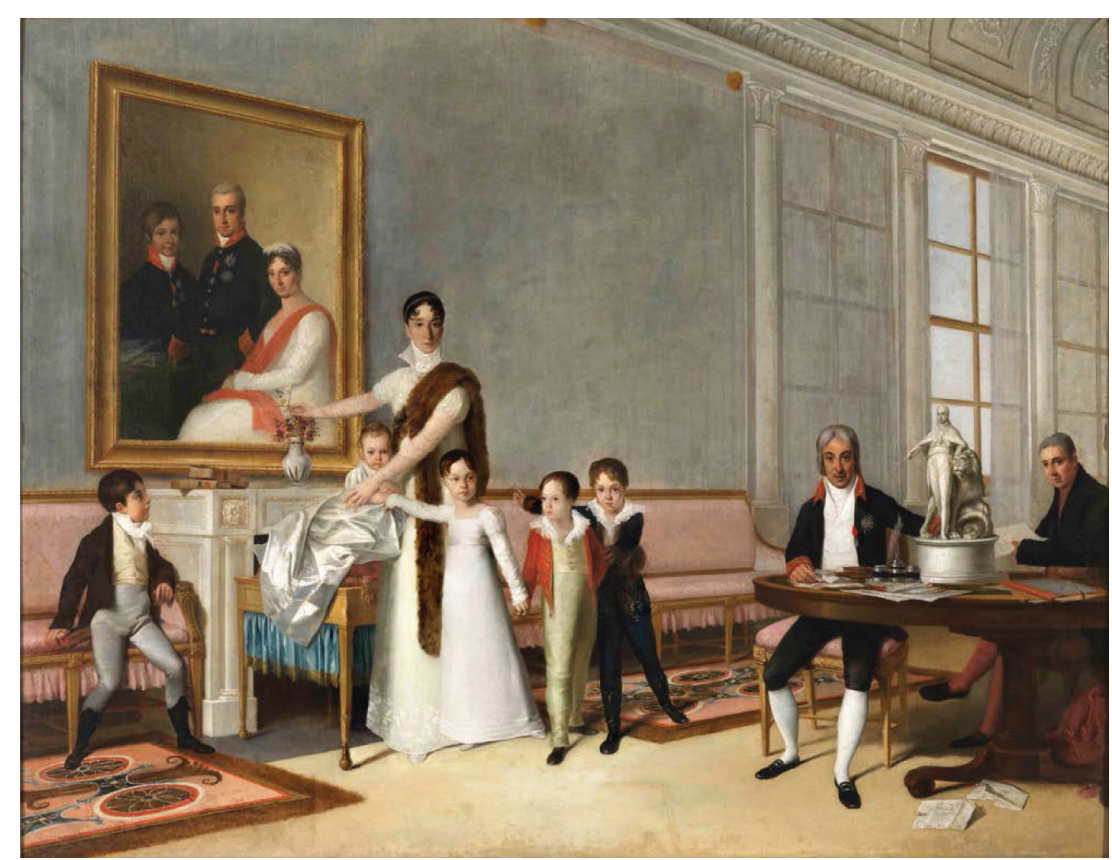

Picture C: Portrait of the the first Viscount of Santarém and his family in his residence (1816, Retrato de família dos 1 os Viscondes de Santarém, painted by Domingos Sequera)

Reproduced with kind permission of the Museu Nacional de Arte Antiga, Lisbon 


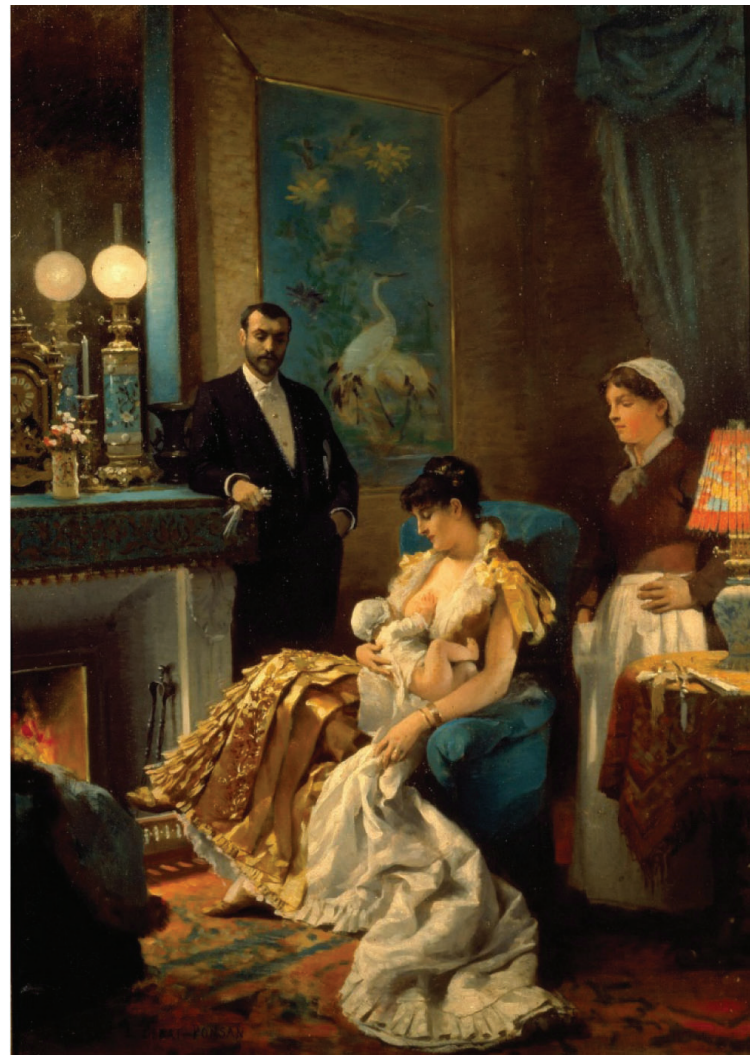

Picture D: Painting of a middle-class family by the fireplace, with a maid (1886, Avant le bal, painted by Edouard Debat-Ponsan)

Reproduced with kind permission of the Musée des Beaux Arts de Tours, France

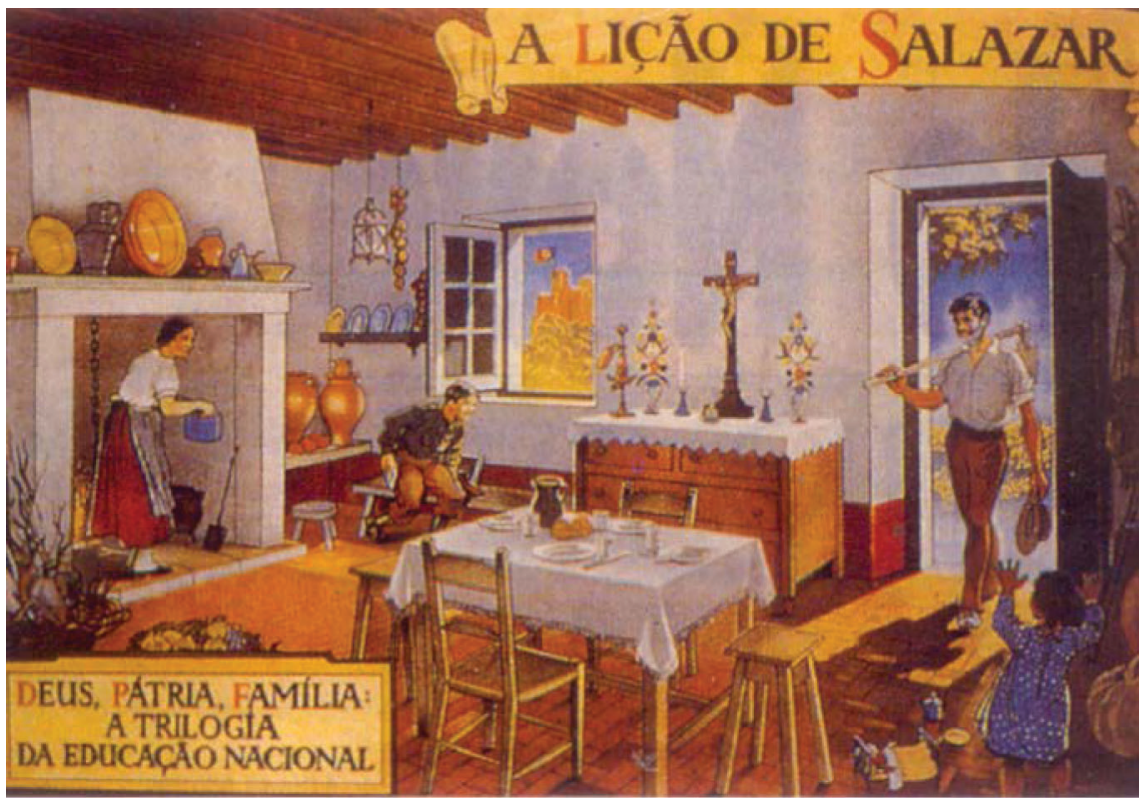

Picture E: Propaganda poster of the New State with a rural family (1938, A lição de Salazar: Deus, Pátria, Família - a trilogia da educação nacional, painted by Jaime Martins Barata)

Reproduced with kind permission of the artist's family 


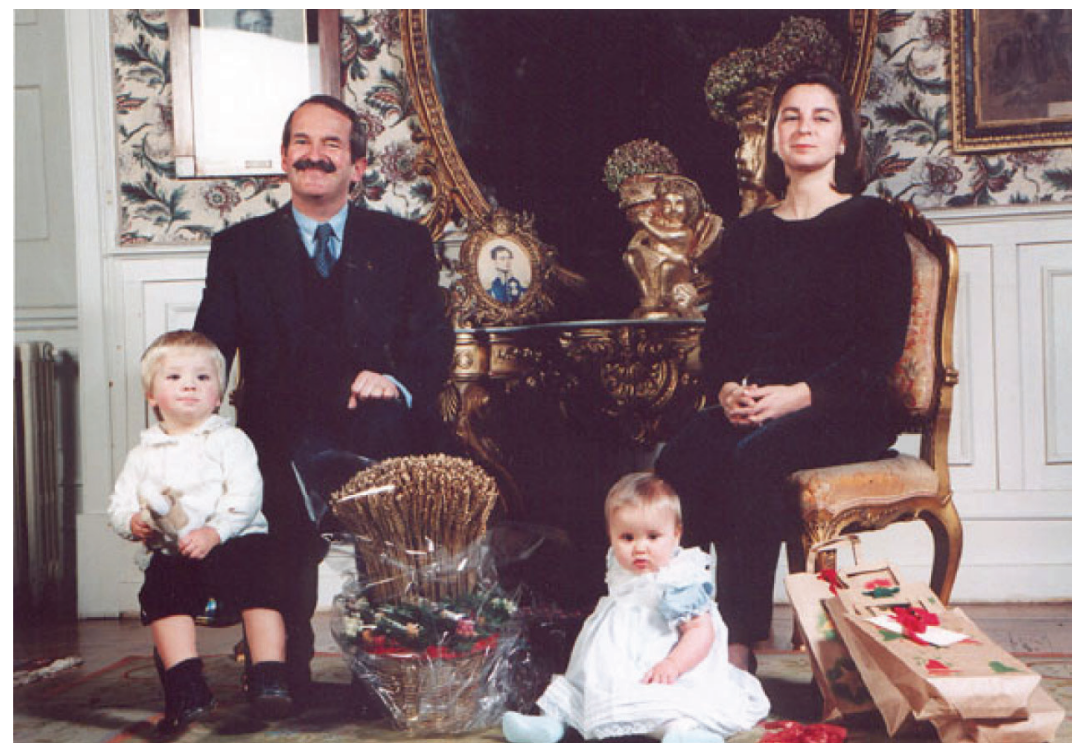

Picture F: Family of the current Duke of Bragança at their home (1999, photographed by António Homem Cardoso)

Reproduced with kind permission of the Secretariat of the Portuguese Royal Household (Secretariado da Casa Real Portuguesa)

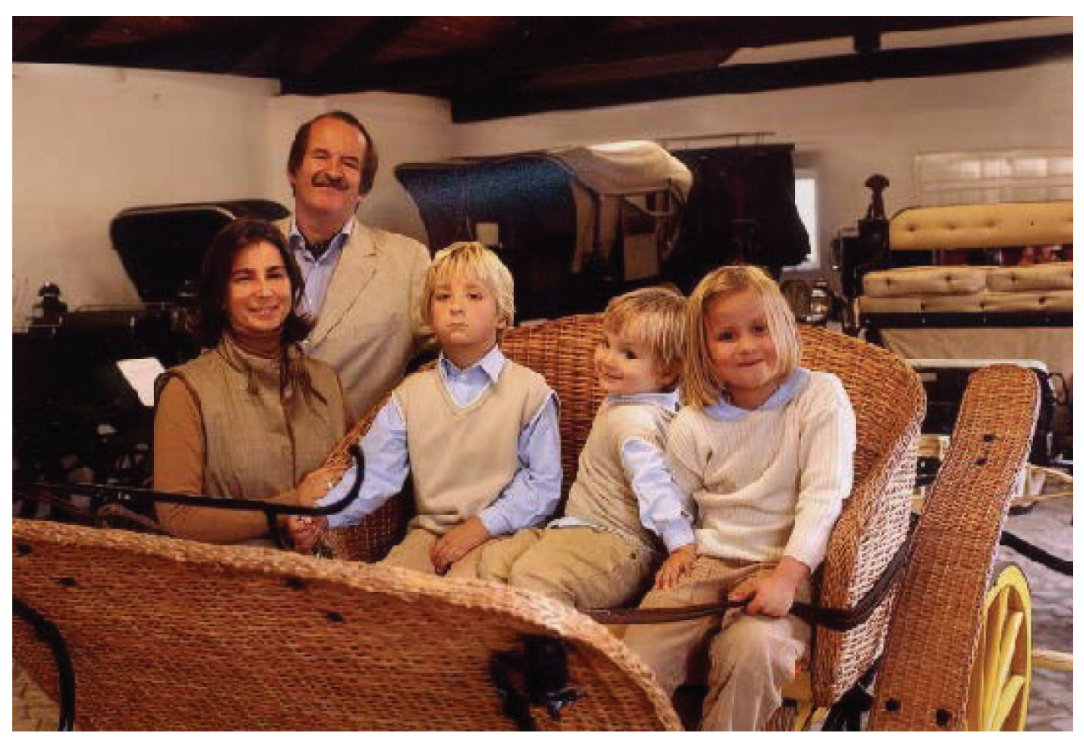

Picture G: Family of the current Duke of Bragança at their home (2003, photographed by António Homem Cardoso)

Reproduced with kind permission of the Secretariat of the Portuguese Royal Household (Secretariado da Casa Real Portuguesa) 